\title{
BMJ Open Geographic and socioeconomic variation of sodium and potassium intake in Italy: results from the MINISAL-GIRCSI programme
}

Francesco P Cappuccio, ${ }^{1}$ Chen $\mathrm{Ji}^{1}{ }^{1}$ Chiara Donfrancesco, ${ }^{2}$ Luigi Palmieri, ${ }^{2}$
Renato Ippolito, ${ }^{3}$ Diego Vanuzzo, ${ }^{4}$ Simona Giampaoli, ${ }^{2}$ Pasquale Strazzullo ${ }^{3}$

To cite: Cappuccio FP, Ji C, Donfrancesco C, et al. Geographic and socioeconomic variation of sodium and potassium intake in Italy: results from the MINISAL-GIRCSI programme. BMJ Open 2015;5:e007467. doi:10.1136/bmjopen-2014007467

- Prepublication history and additional material is available. To view please visit the journal (http://dx.doi.org/ 10.1136/bmjopen-2014007467)

FPC and CJ contributed equally.

Received 17 December 2014 Revised 14 May 2015 Accepted 19 May 2015

\section{CrossMark}

For numbered affiliations see end of article.

Correspondence to Professor Francesco P Cappuccio;

f.p.cappuccio@warwick.ac.uk

\section{ABSTRACT}

Objectives: To assess geographic and socioeconomic gradients in sodium and potassium intake in Italy.

Setting: Cross-sectional survey in Italy.

Participants: 3857 men and women, aged 39-

79 years, randomly sampled in 20 regions (as part of a National cardiovascular survey of 8714 men and women).

Primary outcome measures: Participants' dietary sodium and potassium intakes were measured by $24 \mathrm{~h}$ urinary sodium and potassium excretions. 2 indicators measured socioeconomic status: education and occupation. Bayesian geoadditive models were used to assess spatial and socioeconomic patterns of sodium and potassium intakes accounting for sociodemographic, anthropometric and behavioural confounders.

Results: There was a significant north-south pattern of sodium excretion in Italy. Participants living in southern Italy (eg, Calabria, Basilicata and Puglia $>180 \mathrm{mmol} /$ $24 \mathrm{~h}$ ) had a significantly higher sodium excretion than elsewhere (eg, Val d'Aosta and Trentino-Alto Adige $<140 \mathrm{mmol} / 24 \mathrm{~h} ; \mathrm{p}<0.001$ ). There was a linear association between occupation and sodium excretion $(\mathrm{p}<0.001)$. When compared with occupation I (top managerial), occupations III and IV had a $6.5 \%$ higher sodium excretion (coefficients: $0.054(90 \%$ credible levels $0.014,0.093)$ and $0.064(0.024,0.104)$, respectively). A similar relationship was found between educational attainment and sodium excretion $(p<0.0001)$. When compared with those with a university degree, participants with primary and junior school education had a $5.9 \%$ higher urinary sodium (coefficients: $0.074(0.031,0.116)$ and $0.038(0.001$, $0.075)$, respectively). The socioeconomic gradient explained the spatial variation. Potassium excretion was higher in central regions and in some southern regions. Those in occupation V (low-skill workers) showed a 3\% lower potassium excretion compared with those in occupation I. However, the socioeconomic gradient only partially explained the spatial variation.

Conclusions: Salt intake in Italy is significantly higher in less advantaged social groups. This gradient is independent of confounders and explains the geographical variation.

\section{Strengths and limitations of this study}

- The MINISAL-GIRCSI survey is a populationbased study designed specifically to assess sodium and potassium intake.

- The dietary assessment was carried out using the gold standard biomarker of $24 \mathrm{~h}$ urinary excretion of sodium and potassium, strictly following recent guidelines from the WHO.

- The geographic proportional sampling from all regions of Italy for both sexes offers national generalisability to the findings.

- The choice of the analytical method of a Bayesian geoadditive model allows the simultaneous assessment of spatial (geographic) variations, socioeconomic status (SES) variations, and the linear and non-linear effects of measured and unmeasured confounders.

- A limitation is the unavailable dietary assessment of sources of sodium and potassium so that, for sodium in particular, we cannot attribute the differences in salt intake to discretionary or dietary sources.

- Also, definitions of SES were based on the head of the household's occupation and participant's educational attainment.

- The possibility of residual confounding cannot be categorically ruled out.

\section{BACKGROUND}

Health inequalities by socioeconomic status (SES) are common. The Marmot Review in the $\mathrm{UK}^{1}$ and the work of the Commission on Social Determinants of Health of the $\mathrm{WHO}^{2}$ have highlighted the presence of a social gradient in health inequalities both within and between countries. People of poorer background die sooner and also spend more of their lives with disabilities. Health inequalities are the result of complex interactions of many factors, one of which is poor diet and nutrition. Inequalities in nutrition and SES translate ultimately into inequalities in 
health. ${ }^{3}$ In particular, cardiovascular disease is more prevalent in socioeconomically deprived people and groups, including a high risk of stroke, renal failure and hypertension. ${ }^{3}$ The latter is the most common attributable cause of cardiovascular death and disability. ${ }^{4}$

Nutritional factors have been causally related to high blood pressure (BP) and, among these, dietary electrolyte intake. ${ }^{5}$ In particular, epidemiological, clinical and experimental evidence supports a causal relationship between dietary sodium (Na) chloride (salt) intake and high BP. $^{6}$ The INTERSALT Study showed a direct association between average population salt intake and the increase of BP with age. ${ }^{7}$ Randomised controlled clinical trials of reductions in $\mathrm{Na}$ intake have documented a significant BP lowering effect in hypertensive and nonhypertensive individuals. ${ }^{8}$ Population-based prospective studies also show that a $5 \mathrm{~g}$ /day higher salt intake is associated with a $23 \%$ greater risk of stroke. ${ }^{89}$

Habitual dietary potassium (K) intake has also been associated with improved cardiovascular health. In prospective studies, a $1.6 \mathrm{~g} /$ day higher habitual $\mathrm{K}$ intake was associated with a $21 \%$ lower risk of stroke. ${ }^{10}$ Protection against stroke is attributable to the favourable effect of $\mathrm{K}$ on BP, as indicated by numerous studies, including the Dietary Approaches to Stop Hypertension (DASH) trial ${ }^{11}$ and a 1-year long randomised controlled trial showing satisfactory BP control with significantly lower drug consumption in hypertensive patients given a fruit and vegetable K-rich diet compared with a control group. ${ }^{12}$

There is evidence for SES gradients of habitual $\mathrm{Na}$ and $\mathrm{K}$ intake in the USA. ${ }^{13}$ In Britain, in the 2000-2001 National Dietary and Nutrition Survey, salt intake was higher in low socioeconomic groups after allowing for geographic gradients. ${ }^{14}$ Crucially, after a 8 -year salt reduction programme, while dietary as well as total (dietary plus discretionary) salt consumptions have decreased by 0.9 and $1.5 \mathrm{~g} /$ day, respectively, social inequalities remained. ${ }^{15}$ The collection of data on SES gradients in different countries of Europe and their monitoring during policy implementation of salt reduction strategies are important to ensure that the gaps are corrected or at least not inadvertently widened. ${ }^{16}$

The present study exploits the findings of the MINISAL-GIRCSI programme, a national survey of habitual $\mathrm{Na}$ and $\mathrm{K}$ intake recently carried out in Italy ${ }^{17}$ to address the question of whether social inequalities affect electrolyte intake, independent of geographic variations.

\section{DATA AND METHODS}

\section{Population data}

Between 2008 and 2012, the Italian National Institute of Health (ISS) in collaboration with the National Association of Hospital Cardiologists (ANMCO) carried out a Cardiovascular Epidemiology/Health Examination Survey (OEC/HES) and investigated randomly selected age-specific and sex-specific samples of 220 men and women per 1.5 million residents of 17 Italian regions (Friuli Venezia Giulia, Molise, Sicilia, Emilia Romagna, Calabria, Basilicata, Piemonte, Sardegna, Marche, Veneto, Lazio, Umbria, Campania, Liguria, Puglia, Trentino-Alto Adige and Lombardia). A further survey was performed with identical criteria within the framework of the Meno Sale Più Salute Programme in Val d'Aosta, Toscana and Abruzzo, for a total of 20 regions and a final overall study population of 4368 men and 4346 women, aged $35-79$ years. ${ }^{18}$

For the purposes of the MINISAL-GIRCSI and Meno Sale Più Salute studies, a randomly selected subsample of 100 men and 100 women stratified by age and sex was used for each region, based on the WHO recommendation that a sample of 100-200 individuals is required to estimate sodium intake with a $95 \%$ CI about the mean of consumption of $\pm 12 \mathrm{mmol} /$ day using a single $24 \mathrm{~h}$ urine collection. ${ }^{19}$

In addition to a $24 \mathrm{~h}$ urine collection, this subproject contained a questionnaire covering sociodemographic information (age, sex, level of education, occupation), lifestyles (physical activity at work, alcohol consumption, smoking habit) and anthropometric and BP measurements. Anthropometric measurements were performed in underwear: height by stadiometer, rounded to the nearest centimetre, weight was measured by a balance beam scale recorded in kilogram and rounded to the nearest $200 \mathrm{~g}$. Body mass index (BMI) was calculated on the basis of height and weight (weight $(\mathrm{kg}) / \mathrm{height}$ $\left.\left(\mathrm{m}^{2}\right)\right)$. BP was measured three times on the right arm in sitting position, after 5 min rest, with a mercury sphygmomanometer, and their average was recorded. Hypertension was defined if the participant was on hypertension medication, or had BP $\geq 140 / 90 \mathrm{~mm} \mathrm{Hg}$. Participants' smoking habit was coded as current smoker, former smoker and never smoked. Daily alcohol consumption was reported in grams.

Each participant's marital status was described by one of the following categories: married/cohabited, single, separated/divorced, and widowed. SES was measured by two indicators: education and occupation. By answering the question of educational attainment, participants were coded as university degree, high school, junior high school, or primary school or equivalent. The occupation of the participants was coded into eight occupational categories: top managerial occupations, white collars or civil servants, low managerial occupations, high-skill workers, low-skill workers and others (including student, housewife, unemployed, disabled and those temporarily laid off). Since housewives accounted for more than $10 \%$ of the total study population, these participants were grouped as 'housewife' in the occupation variable. The rest in the 'others', where the majority did not provide information of occupation, were treated as missing values.

Each participant's physical activity during work was measured by four levels: work performed mainly sitting at a desk and generally without the need to walk 
(inactive), work that implies standing and walking for a long time (mildly active), work that implies a lot of walking and handling heavy weights (moderately active), and hard manual work, with great efforts and lifting and handling heavy weights (vigorously active). For the retired participants, the physical activity information was based on their last job. Twenty-four-hour urinary $\mathrm{Na}$ and $\mathrm{K}$ excretions were derived from the product of the urinary $\mathrm{Na}$ and $\mathrm{K}$ concentrations and urine volume. Any urine collections less than $500 \mathrm{~mL}$ or with a creatinine excretion lower than the population mean minus two SDs were discarded to ensure the completeness of the collection. $^{20}$ The final sample of this subproject was 3857 , that is, the subject of the present report. Other methodological features of the survey have been detailed elsewhere. ${ }^{17} 20$

\section{Statistical methods}

Preliminary analysis was performed in SPSS (V.22, Armonk, New York, USA: IBM Corp). The Kruskal-Wallis test was used to compare $24 \mathrm{~h}$ urinary $\mathrm{Na}$ and $\mathrm{K}$ excretions across all regions. The model estimation was performed in BayesX (V.2.1). ${ }^{21}$ Bayesian geoadditive mixed models were used to assess the spatial effect, SES pattern and non-linear effects of covariates of $\mathrm{Na}$ and $\mathrm{K}$ excretion. $^{21}{ }^{22}$ Briefly, the overall spatial effect consists of a correlated spatial effect and an uncorrelated (ie, random) spatial effect, which represent an underlying spatial structure and a locally present effect, respectively. Based on the Markov Chain Monte Carlo (MCMC) simulation, this class of models provides a unified framework for modelling linear and non-linear effects simultaneously, as well as the underlying spatial process. A more detailed introduction has been described elsewhere. ${ }^{14}{ }^{15}$ A reference level was specified for each categorical factor: sex (reference $=$ female), smoking habit (never smoked), education (university degree), occupation (top managerial occupations), marital status (married/cohabited), physical activity (inactive) and hypertension (no hypertension).

To adjust for different factors and covariates, as well as linear, non-linear and spatial effects, six models were built and compared for both $24 \mathrm{~h} \mathrm{Na}$ and $\mathrm{K}$. The model with lower deviance information criterion (DIC) was preferred. Models 1-4 included spatial and linear effects only. In model 4, occupation was first included (model $4 a)$ and then replaced by education (model $4 \mathrm{~b}$ ). This was to assess and compare different SES effects on Na and $\mathrm{K}$ by different SES measurements. Twenty-four-hour urinary $\mathrm{Na}$ and $\mathrm{K}$ excretions were log-transformed to be normally distributed. The details of models' definition and DIC results are presented in online supplementary appendix S1. The Bayesian inference calculates the probability of different values of the measured parameter 'given' the data. This probability distribution is called the 'a posteriori probability' or simply the 'posterior'. Bayesian approaches can summarise their uncertainty by giving a range of values on the posterior probability distribution that includes $95 \%$ of the probability—-this is called a ' $95 \%$ credibility interval'.

\section{Spatial boundaries}

Participants were recruited from 20 administrative regions (table 1). Sicilia and Sardegna do not share any land border with other regions. To include them in the analysis, neighbouring regions were defined for each region using R (R2 BayesX package). ${ }^{21}$ Hence, Calabria was considered as the only neighbour to Sicilia, and Lazio, Liguria and Toscana were considered neighbours to Sardegna. Alternative sets of neighbours of Sardegna, that is, Lazio and Toscana or Lazio only, were used in the models to test the sensitivity of the neighbour definition.

\section{RESULTS}

\section{Basic characteristics}

The characteristics of the participants are presented in table 1. In total, 1894 women and 1963 men, aged from 39 to 79 years, were included in the analysis. Aside from the $14.6 \%$ university degree holders, there was an increasing trend of educational attainment from the primary school to high school certificates. High-skill workers, white collars/civil servants and low-skill workers were the top three occupations. The median $24 \mathrm{~h}$ urinary $\mathrm{Na}$ excretion was $154.1 \mathrm{mmol} /$ day (approximately $9 \mathrm{~g}$ of salt per day, $1 \mathrm{~g}$ salt $=17.1 \mathrm{mmol} \mathrm{Na}$ ). The median $24 \mathrm{~h}$ urinary $\mathrm{K}$ excretion was $57.6 \mathrm{mmol} /$ day (approximately $2.25 \mathrm{~g}$ of $\mathrm{K}$ per day, $1 \mathrm{mmol}=39 \mathrm{mg}$ of $\mathrm{K}$ ). The median $24 \mathrm{~h}$ urinary $\mathrm{Na}$ and $\mathrm{K}$ excretion varied significantly across all regions $(\mathrm{p}<0.001$ for both; table 2$)$.

Three neighbouring southern regions, Calabria, Basilicata and Puglia, had the highest level of urinary $\mathrm{Na}$ excretion (figure 1 and table 2) and Friuli Venezia Giulia had the lowest level of $\mathrm{K}$ excretion (table 2). The map suggests an increasing north-south pattern of $24 \mathrm{~h}$ urinary $\mathrm{Na}$ excretion and a higher urinary $\mathrm{K}$ excretion in the central regions.

By comparing the (DIC) values of the models, model 4a performed the best (see online supplementary appendix S2). However, both models $4 \mathrm{a}$ and $4 \mathrm{~b}$ will be presented here to show the effects of both SES indicators on $24 \mathrm{~h}$ urinary $\mathrm{Na}$ and $\mathrm{K}$ excretion.

\section{Determinants of sodium excretion}

As the Bayesian models do not produce any $\mathrm{p}$ values, statistical significance for the fixed $\mathrm{Na}$ effect was determined by the position of the overall $90 \%$ credible intervals (table 3). Age, sex and BMI were significantly associated with $24 \mathrm{~h}$ urinary $\mathrm{Na}$ excretion. Men, younger participants or those with higher BMI were more likely to have a higher $\mathrm{Na}$ intake (table 3 ).

Although model 4a performed better than model 4b, both SES indicators, occupation and education, showed a significant independent association with $24 \mathrm{~h}$ urinary $\mathrm{Na}$ excretion. With the exclusion of housewives, those in 
Table 1 Basic characteristics of the Italian observatory epidemiological cardiovascular/Health Examination Survey 2008-2012 ( $\mathrm{N}=3857)$

\begin{tabular}{|c|c|}
\hline Age (year) & $56.5(12.5)$ \\
\hline \multicolumn{2}{|l|}{ Sex $(\%)$} \\
\hline Female & 49.1 \\
\hline Male & 50.9 \\
\hline Height (cm) & $164.1(10.0)$ \\
\hline Weight (kg) & $74.3(15.2)$ \\
\hline BMI $\left(\mathrm{kg} / \mathrm{m}^{2}\right)$ & $27.6(5.0)$ \\
\hline $\mathrm{SBP}(\mathrm{mm} \mathrm{Hg})$ & $131.7(19.0)$ \\
\hline $\mathrm{DBP}(\mathrm{mm} \mathrm{Hg})$ & $81.2(10.3)$ \\
\hline \multicolumn{2}{|l|}{ Smoking habit (\%) } \\
\hline Current & 20.2 \\
\hline Former & 30.0 \\
\hline Never & 49.8 \\
\hline Alcohol consumption(g/day)* & $10.5(5.4)$ \\
\hline \multicolumn{2}{|l|}{ Education (\%) } \\
\hline University degree & 14.6 \\
\hline High school & 33.7 \\
\hline Junior high school & 28.0 \\
\hline Primary school or equivalent & 23.7 \\
\hline \multicolumn{2}{|l|}{ Occupation (\%) } \\
\hline Top managerial occupations & 14.8 \\
\hline White collars/civil servants & 23.3 \\
\hline Low managerial occupations & 2.7 \\
\hline High-skill workers & 25.0 \\
\hline Low-skill workers & 20.3 \\
\hline Housewife & 13.8 \\
\hline \multicolumn{2}{|l|}{ Marital status (\%) } \\
\hline Married/cohabitant & 77.0 \\
\hline Single & 10.1 \\
\hline Separated/divorced & 5.5 \\
\hline Widowed & 7.3 \\
\hline \multicolumn{2}{|l|}{ Physical activity at work (\%) } \\
\hline Inactive & 31.8 \\
\hline Mildly active & 44.1 \\
\hline Moderately active & 18.9 \\
\hline Vigorously active & 5.2 \\
\hline \multicolumn{2}{|l|}{ Hypertension (\%) } \\
\hline No & 50.5 \\
\hline Yes & 49.5 \\
\hline $24 \mathrm{~h} \mathrm{Na}$ (mmol/day) & 154.1 (83.8) \\
\hline $24 \mathrm{~h} \mathrm{~K}$ (mmol/day) & $57.6(23.8)$ \\
\hline 24 h Cr (mg/day) & $10.5(5.4)$ \\
\hline \multicolumn{2}{|l|}{ Sample by region (\%) } \\
\hline Abruzzo & 5.2 \\
\hline Basilicata & 4.0 \\
\hline Calabria & 4.9 \\
\hline Campania & 5.1 \\
\hline Emilia-Romagna & 4.8 \\
\hline Friuli-Venezia Giulia & 4.8 \\
\hline Lazio & 5.1 \\
\hline Liguria & 5.3 \\
\hline Lombardia & 5.4 \\
\hline Marche & 5.0 \\
\hline Molise & 5.0 \\
\hline Piemonte & 5.2 \\
\hline Puglia & 5.0 \\
\hline Toscana & 5.5 \\
\hline Trentino-Alto Adige & 5.6 \\
\hline Umbria & 4.7 \\
\hline
\end{tabular}

Val d'Aosta

4.6

Veneto

5.4

Sardegna

4.7

Sicilia

5.0

*Alcohol consumption and urinary electrolytes were shown as median (IQR).

$\mathrm{BMI}$, body mass index; $\mathrm{Cr}$, urinary creatinine; DBP, diastolic blood pressure; $\mathrm{Na}$, urinary sodium; SBP, systolic blood pressure.

occupations III and IV had higher $24 \mathrm{~h}$ urinary $\mathrm{Na}$ excretion (reflecting higher salt intake) compared with occupations I and II (figure 2, top left panel; p for linear trend $<0.001 ; \mathrm{F}=16.5 ; \mathrm{df}=4)$. When compared with occupation I (white collars and civil servants), occupations III and IV had, on average, a 5.6\% and 6.6\% higher salt intake, respectively. Likewise, those with a lower level of education (occupations III and IV) had higher salt intake compared with those with the highest level of education (figure 2, top right panel; $p$ for linear trend $<0.0001 ; \mathrm{F}=8.5 ; \mathrm{df}=3$ ). When compared with those with a university degree, those with primary and junior school education had, on average, a $3.9 \%$ and $7.7 \%$ higher salt intake, respectively.

\section{Determinants of potassium excretion}

$\mathrm{K}$ excretion did not vary by age; however, sex, BMI and alcohol consumption were significantly associated with $24 \mathrm{~h}$ urinary $\mathrm{K}$ excretion (table 4). Men, those with higher BMI and who were drinking more were more likely to have a higher $\mathrm{K}$ intake. Hypertensive individuals had a lower K excretion. There was no consistent association between $\mathrm{K}$ excretion and SES ( $\mathrm{p}$ for linear trend $=0.04$ and 0.053 for occupation and educational attainment, respectively; figure 2, bottom panels); however, participants with primary and junior school education had significantly lower K compared with those with a university degree (figure 2 , bottom right panel). The difference was $2.6 \%$.

\section{Spatial map of $24 \mathrm{~h}$ urinary sodium excretion}

Model 1 only accounted for the spatial effect. Figure 3 (top panel) shows the estimated mean effect map (left) and the probability map of the structured spatial effect (right). Twenty-four-hour urinary $\mathrm{Na}$ was higher in the south and lower in the central and northern regions. In particular, the probability map suggested a significantly higher $\mathrm{Na}$ level in three southern regions (shown as white colour).

Although the posterior means still showed a higher level of $\mathrm{Na}$ in the southern regions for models $4 \mathrm{a}$ and $4 \mathrm{~b}$, the probability map suggested no significant spatial variation after controlling for SES variables (figure 3, middle and bottom panels). In other words, geographic variations in salt intake across Italy are explained by SES variations and are attenuated or disappear once this relationship is taken into account. 
Table 2 Twenty-four-hour urinary sodium and potassium excretions by region and equivalent dietary salt and potassium intake

\begin{tabular}{|c|c|c|c|c|}
\hline Region & $\begin{array}{l}24 \mathrm{~h} \text { urinary sodium } \\
\text { excretion (mmol/day) }\end{array}$ & $\begin{array}{l}\text { Average salt } \\
\text { intake (g/day) } \dagger\end{array}$ & $\begin{array}{l}24 \mathrm{~h} \text { urinary potassium } \\
\text { excretion }(\mathrm{mmol} / \mathrm{day})^{\star}\end{array}$ & $\begin{array}{l}\text { Average potassium } \\
\text { intake }(\mathrm{g} / \text { day }) \dagger\end{array}$ \\
\hline Abruzzo & $127.4(78.9)$ & 7.84 & $62.2(30.2)$ & 3.15 \\
\hline Basilicata & $182.6(81.8)$ & 11.24 & $55.3(20.9)$ & 2.80 \\
\hline Calabria & $182.8(98.7)$ & 11.25 & $58.2(22.8)$ & 2.95 \\
\hline Campania & $162.0(92.1)$ & 9.97 & $60.9(27.5)$ & 3.09 \\
\hline Emilia-Romagna & $159.4(81.1)$ & 9.81 & 54.7 (22.7) & 2.77 \\
\hline Friuli-Venezia Giulia & $153.1(90.2)$ & 9.42 & $51.5(23.3)$ & 2.61 \\
\hline Lazio & 147.5 (78.4) & 9.08 & $61.0(21.1)$ & 3.09 \\
\hline Liguria & $146.9(69.5)$ & 9.04 & $54.1(21.0)$ & 2.74 \\
\hline Lombardia & $142.2(80.0)$ & 8.75 & $53.1(21.8)$ & 2.69 \\
\hline Marche & $156.5(85.8)$ & 9.63 & $60.1(21.6)$ & 3.05 \\
\hline Molise & $141.5(64.0)$ & 8.71 & 55.9 (26.0) & 2.83 \\
\hline Piemonte & $167.4(81.3)$ & 10.30 & $56.3(25.9)$ & 2.85 \\
\hline Puglia & $182.0(94.1)$ & 11.20 & $60.2(23.3)$ & 3.05 \\
\hline Toscana & $143.1(76.6)$ & 8.81 & $59.5(28.8)$ & 3.02 \\
\hline Trentino-Alto Adige & $138.3(78.8)$ & 8.51 & $56.0(19.5)$ & 2.84 \\
\hline Umbria & $157.0(81.4)$ & 9.66 & $57.6(25.0)$ & 2.92 \\
\hline Val d'Aosta & $131.7(73.4)$ & 8.11 & $57.2(21.9)$ & 2.90 \\
\hline Veneto & $156.3(82.4)$ & 9.62 & $61.8(20.6)$ & 3.13 \\
\hline Sardegna & $131.8(84.2)$ & 8.11 & $55.8(23.3)$ & 2.83 \\
\hline Sicilia & 178.8 & 11.00 & $56.6(25.4)$ & 2.87 \\
\hline
\end{tabular}

${ }^{*}$ Values are reported as median (IQR). $\mathrm{p}$ Values for the medians of $24 \mathrm{~h}$ urinary sodium and potassium excretions across all Italian regions are both $<0.001$ by the Kruskal-Wallis test.

tWe estimated intake from $24 \mathrm{~h}$ urinary excretion by using a conversion factor of 1.05 for sodium and of 1.3 for potassium. $17.1 \mathrm{mmol}$ of $\mathrm{Na}=0.4 \mathrm{~g}$ of sodium equivalent to $1 \mathrm{~g}$ of salt; $1 \mathrm{mmol}$ of $\mathrm{K}=39 \mathrm{mg}$ of $\mathrm{K}^{52}$

\section{Spatial map of $24 \mathrm{~h}$ urinary potassium}

There was no significant spatial variation of $\mathrm{K}$ intake in Italy based on the results of model 1 , although the central and southern regions showed higher salt intake than other regions (see online supplementary appendix S3). After controlling for the SES variables, the models


Figure 1 Observed median $24 \mathrm{~h}$ urinary sodium (left) and potassium (right) excretion by region. Red (green) indicates a high (low) level of $24 \mathrm{~h}$ urinary sodium (left) and potassium (right) excretion. 
Table 3 Estimated posterior means and $90 \%$ credible intervals of fixed factors for sodium excretion by occupation and educational attainment

\begin{tabular}{|c|c|c|}
\hline & $\begin{array}{l}\text { Occupation } \\
\text { Mean coefficient } \\
\text { (90\% credible intervals) }\end{array}$ & $\begin{array}{l}\text { Educational attainment } \\
\text { Mean coefficient } \\
\text { (90\% credible intervals) }\end{array}$ \\
\hline Age (year) & $-0.003(-0.004,-0.002)$ & $-0.004(-0.005,-0.003)$ \\
\hline \multicolumn{3}{|l|}{ Sex } \\
\hline Female & Reference & Reference \\
\hline Male & $0.248(0.218,0.277)$ & $0.251(0.228,0.273)$ \\
\hline BMI $\left(\mathrm{kg} / \mathrm{m}^{2}\right)$ & $0.018(0.015,0.020)$ & $0.019(0.017,0.021)$ \\
\hline Alcohol consumption (g/day) & $-0.0004(-0.001,0.0002)$ & $-0.0004(-0.001,0.0002)$ \\
\hline \multicolumn{3}{|l|}{ Smoking habit } \\
\hline Never & Reference & Reference \\
\hline Former & $0.032(0.004,0.060)$ & $0.026(0.0002,0.050)$ \\
\hline Current & $0.033(0.0004,0.064)$ & $0.017(-0.010,0.044)$ \\
\hline \multicolumn{3}{|l|}{ Marital status } \\
\hline Married/cohabited & Reference & Reference \\
\hline Single & $-0.043(-0.083,-0.004)$ & $-0.043(-0.078,-0.007)$ \\
\hline Separated/divorced & $-0.064(-0.115,-0.012)$ & $-0.046(-0.092,-0.003)$ \\
\hline Widowed & $-0.035(-0.084,0.015)$ & $-0.038(-0.079,0.004)$ \\
\hline \multicolumn{3}{|l|}{ Occupation } \\
\hline Top managerial occupations & Reference & - \\
\hline White collars/civil servants (I) & $-0.001(-0.038,0.039)$ & - \\
\hline Low managerial occupations (II) & $0.026(-0.060,0.106)$ & - \\
\hline High-skill workers (III) & $0.054(0.014,0.093)$ & _- \\
\hline Low-skill workers (IV) & $0.064(0.024,0.104)$ & - \\
\hline Housewife (NA) & $0.038(-0.012,0.084)$ & - \\
\hline \multicolumn{3}{|l|}{ Education } \\
\hline University degree (I) & - & Reference \\
\hline High school (II) & - & $0.009(-0.023,0.043)$ \\
\hline Junior high school (III) & - & $0.038(0.001,0.075)$ \\
\hline Primary school or equivalent (IV) & - & $0.074(0.031,0.116)$ \\
\hline \multicolumn{3}{|l|}{ Physical activity } \\
\hline Inactive & Reference & Reference \\
\hline Mildly active & $0.034(0.006,0.064)$ & $0.044(0.020,0.070)$ \\
\hline Moderately active & $0.041(0.003,0.078)$ & $0.054(0.022,0.085)$ \\
\hline Vigorously active & $0.027(-0.030,0.083)$ & $0.049(-0.001,0.100)$ \\
\hline \multicolumn{3}{|l|}{ Hypertension } \\
\hline No & Reference & Reference \\
\hline Yes & $0.004(-0.022,0.031)$ & $-0.006(-0.029,0.016)$ \\
\hline
\end{tabular}

$4 \mathrm{a}$ and $4 \mathrm{~b}$ of $24 \mathrm{~h}$ urinary $\mathrm{K}$ showed a different spatial distribution, compared with the $\mathrm{Na}$ estimated mean maps. The central and southern regions had higher $\mathrm{K}$ excretions. The spatial effect difference between the occupation and education models suggests that education may explain some of the spatial variation.

\section{DISCUSSION}

This study shows in a representative sample of Italian men and women that salt intake-estimated using $24 \mathrm{~h}$ urinary $\mathrm{Na}$ excretion-varies across Italy, being higher in the South. Crucially, the study shows for the first time that salt intake is significantly higher in less advantaged social groups (both by occupation and by level of educational attainment). This social gradient is independent of age, sex, BMI, hypertension and other behavioural variables. Finally, the social gradient explains the geographical variation seen in unadjusted models. The study also describes the geographic and SES variations in $\mathrm{K}$ excretion, a biomarker of $\mathrm{K}$ intake ${ }^{23}$ and a close indicator of fruit and vegetable intake. ${ }^{23} \mathrm{~K}$ intake, an effective protective factor for high $\mathrm{BP}^{24}$ and stroke, ${ }^{10} 24$ is higher in the central and southern regions and lower in those with lower education attainment.

\section{Strengths and limitations}

The study has a number of strengths. The MINISAL-GIRCSI survey is a population-based study ${ }^{17}$ designed specifically to assess $\mathrm{Na}$ and $\mathrm{K}$ intake using the gold standard biomarker of $24 \mathrm{~h}$ urinary excretion of $\mathrm{Na}$ and $\mathrm{K}$, strictly following recent guidelines from the WHO. ${ }^{19}{ }^{25}$ These estimates approximate very closely 



Figure 2 Effects of socioeconomic status by occupation (left panels) and by education (right panels) for sodium (top) and potassium (bottom) excretion. Note: Values are back log-transformed. Top managerial occupations and university degree were the reference levels for occupation and education, respectively. ${ }^{*}$ Significant effect compared with the reference level at $p<0.05$. p For linear trends reported in the panels (excluding housewives).

the total consumption of $\mathrm{Na}$ and $\mathrm{K}$ and they allow the most reliable assessment of population averages-particularly for $\mathrm{Na}$-compared with other methods. ${ }^{26}{ }^{27} \mathrm{Na}$ intake is a combined sum of $\mathrm{Na}$ present in natural food (approximately 10\%), Na added by the consumer when cooking and at the table (approximately 36\%) and that present in processed food as added by the manufacturing process (approximately 54\%). ${ }^{28}$ Hence, dietary assessments would tend to grossly underestimate total salt intake. The geographic proportional sampling from all regions of Italy for both sexes offers national generalisability to the findings. The choice of the analytical method of a Bayesian geoadditive model allows the simultaneous assessment of spatial (geographic) variations, SES variations, and the linear and non-linear effects of measured and unmeasured confounders. One limitation is the unavailable dietary assessment of sources of $\mathrm{Na}$ and $\mathrm{K}$ so that, for $\mathrm{Na}$ in particular, we cannot attribute the differences in salt intake to discretionary or dietary sources of $\mathrm{Na}$. Also, definitions of SES were based on the head of the household's occupation and participant's educational attainment. While limited, ${ }^{29} 30$ these measures have been consistently used in Italian national surveys. ${ }^{31}$ They are also consistent with measures in other studies. ${ }^{14}$ Finally, the possibility of residual confounding cannot be categorically ruled out.

\section{Context}

The results of the MINISAL-GIRCSI survey confirm high levels of dietary salt intake in Italy when compared with the targets set by the WHO. ${ }^{19}{ }^{25}$ Furthermore, there is substantial geographic variation, mostly accounted for by SES variations. For $\mathrm{K}$ intake, the average levels are also lower than recommended by the $\mathrm{WHO}^{32}$ with both geographic and SES variation. These results are of interest since the Mediterranean diet of southern Italy, as described in the Seven Countries study, has been traditionally considered as very close to if not the ideal diet. $^{33}$ At the time, however, the salt content of food had not been considered, and emphasis was placed on the good balance between saturated fat and fruit and vegetables. Things have changed since the 1960s and 1970s socioeconomically. On the one hand, we document a high salt intake, higher in the more deprived regions of the south, and a lower than expected $\mathrm{K}$ intake, reflecting a reduced consumption of fruit and vegetables. The increasing prevalence of obesity in the southern regions, critical among the younger age groups, ${ }^{34}{ }^{35}$ would support the notion that there has been an increase in 
Table 4 Estimated posterior means and 90\% credible intervals of fixed factors for potassium excretion by occupation and educational attainment

\begin{tabular}{|c|c|c|}
\hline & $\begin{array}{l}\text { Occupation } \\
\text { Mean coefficient } \\
\text { ( } 90 \% \text { credible intervals) }\end{array}$ & $\begin{array}{l}\text { Educational attainment } \\
\text { Mean coefficient } \\
\text { (90\% credible intervals) }\end{array}$ \\
\hline Age (year) & $0.0003(-0.001,0.001)$ & $0.001(-0.0003,0.001)$ \\
\hline \multicolumn{3}{|l|}{ Sex } \\
\hline Female & Reference & Reference \\
\hline Male & $0.090(0.067,0.113)$ & $0.098(0.080,0.115)$ \\
\hline BMI $\left(\mathrm{kg} / \mathrm{m}^{2}\right)$ & $0.010(0.008,0.012)$ & $0.011(0.009,0.013)$ \\
\hline Alcohol consumption (g/day) & $0.001(0.001,0.002)$ & $0.001(0.001,0.001)$ \\
\hline \multicolumn{3}{|l|}{ Smoking habit } \\
\hline Never & Reference & Reference \\
\hline Former & $0.039(0.018,0.062)$ & $0.029(0.009,0.048)$ \\
\hline Current & $0.011(-0.014,0.036)$ & $-0.006(-0.029,0.016)$ \\
\hline \multicolumn{3}{|l|}{ Marital status } \\
\hline Married/cohabited & Reference & Reference \\
\hline Single & $-0.028(-0.060,0.004)$ & $-0.029(-0.056,-0.0003)$ \\
\hline Separated/divorced & $-0.055(-0.095,-0.017)$ & $-0.045(-0.080,-0.007)$ \\
\hline Widowed & $-0.039(-0.075,-0.003)$ & $-0.036(-0.070,-0.002)$ \\
\hline \multicolumn{3}{|l|}{ Occupation } \\
\hline Top managerial occupations (I) & Reference & - \\
\hline White collars/civil servants (II) & $-0.001(-0.032,0.030)$ & - \\
\hline Low managerial occupations (III) & $-0.028(-0.090,0.031)$ & - \\
\hline High-skill workers (IV) & $-0.007(-0.038,0.024)$ & _ \\
\hline Low-skill workers (V) & $-0.002(-0.032,0.030)$ & - \\
\hline Housewives (NA) & $-0.015(-0.053,0.022)$ & - \\
\hline \multicolumn{3}{|l|}{ Education } \\
\hline University degree (I) & - & Reference \\
\hline High school (II) & - & $-0.027(-0.052,-0.001)$ \\
\hline Junior high school (III) & - & $-0.023(-0.051,0.005)$ \\
\hline Primary school or equivalent (IV) & - & $-0.028(-0.061,0.005)$ \\
\hline \multicolumn{3}{|l|}{ Physical activity } \\
\hline Inactive & Reference & Reference \\
\hline Mildly active & $0.006(-0.018,0.030)$ & $0.011(-0.009,0.031)$ \\
\hline Moderately active & $0.011(-0.021,0.041)$ & $0.010(-0.016,0.036)$ \\
\hline Vigorously active & $0.017(-0.030,0.062)$ & $0.035(-0.006,0.076)$ \\
\hline \multicolumn{3}{|l|}{ Hypertension } \\
\hline No & Reference & Reference \\
\hline Yes & $-0.030(-0.051,-0.010)$ & $-0.026(-0.046,-0.006)$ \\
\hline
\end{tabular}

the use of convenience food, likely to be higher in salt and with reduced $\mathrm{K},{ }^{34}$ in addition to the documented increase in calorie intake and physical inactivity. This study was carried out as part of a wider national initiative to increase awareness about the high salt intake of the Italian people, ${ }^{36-38}$ to engage with bread manufacturers to reduce the salt content of bread, ${ }^{39}$ a major source of salt in the Italian diet, to initiate discussions with food manufacturers on voluntary reformulations and to monitor the population salt intake in the years to come to implement an effective surveillance system and policy evaluation. ${ }^{40}$

\section{Implications for policy}

The detection of an SES gradient in salt intake is important for policymakers. An attempt to change individual behaviour through healthy eating campaigns, while useful to increase awareness and reinforce consumer choice, is unlikely to bring about the changes necessary to achieve the recommended targets for salt intake. ${ }^{40}$ They may also widen inequalities. ${ }^{41}{ }^{42}$ Indeed, the diet of socioeconomically disadvantaged groups in Italy, as well as in other European countries, comprises low-quality, salt-dense, high-fat, high-calorie and inexpensive foods. ${ }^{3}{ }^{43-46}$ A greater consumption of bread and other baking products, which, according to the chemical analysis of the national diet performed by the Italian Institute of Nutrition in 1994-1996, is the main source of non-discretionary salt in Italy, ${ }^{47}$ may contribute to the higher salt intake by the lower SES groups. The access to, and consumption of, healthy foods depend on socioeconomic factors. ${ }^{1}$ Data from the Moli-sani study in 
Figure 3 Estimated mean maps (left) and $90 \%$ probability maps (right) of log-transformed $24 \mathrm{~h}$ urinary sodium excretion. Top panel shows the maps using model 1 with spatial effect only; the middle and bottom panels show results using models $4 a$ and $4 \mathrm{~b}$ with occupation and education, respectively. In the mean map, red (green) indicates a high (low) level of $24 \mathrm{~h}$ urinary sodium excretion. In the probability map, grey indicates a non-significant spatial effect, and white (black) indicates a significantly positive (negative) spatial effect at $90 \%$ credible level.
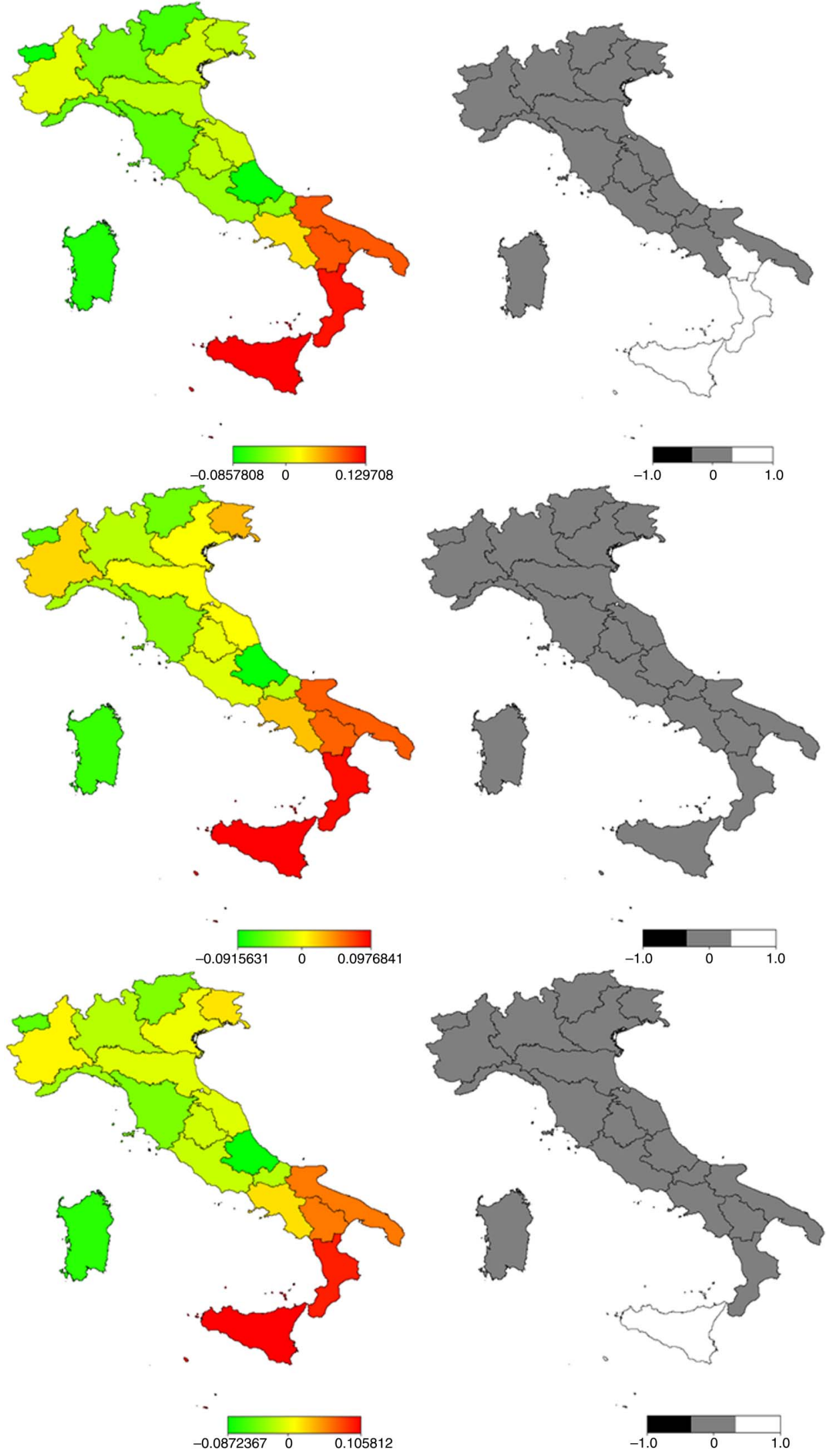

Italy suggest that the quality of the diet worsens during a period of economic hardship. ${ }^{48}$ On the other hand, a 'downstream' approach of reformulation and, if necessary, regulation would be expected to reduce inequalities. ${ }^{4149}{ }^{50}$ It is of interest that in Britain, SES inequalities are still detectable 8 years after a national programme that has achieved overall a $15 \%$ reduction in average salt intake. ${ }^{15}$ The programme was originally 
based on three waves of awareness campaigns, followed by a voluntary agreement with the food industry leading to reformulation of some foods and, more recently, emphasis being given to individual behavioural change through the Responsibility Deal. ${ }^{51}$ The fragmented approach may have resulted in a less effective impact on those who needed to reduce salt intake the most, that is, the low socioeconomic groups.

\section{CONCLUSIONS}

Social inequalities in $\mathrm{Na}$ and, to a lesser extent, in $\mathrm{K}$ intake are present in Italy. It is crucial that the SES patterns of salt intake be taken into account and monitored in the implementation of salt reduction programmes in Italy. In addition, the finding of a surprisingly low dietary $\mathrm{K}$ intake points to the decline of the traditional Mediterranean dietary model with insufficient fruit and vegetable intake, which is coupled with excess consumption of processed and salty foods, especially among the lower socioeconomic groups.

\section{Author affiliations}

${ }^{1}$ University of Warwick, WHO Collaborating Centre for Nutrition, ESH Hypertension Excellence Centre, Warwick Medical School, Coventry, UK ${ }^{2}$ Istituto Superiore di Sanità, National Center of Epidemiology, Rome, Italy ${ }^{3}$ Federico II University of Naples Medical School, ESH Hypertension Excellence Center, Naples, Italy

${ }^{4}$ ANMCO (National Association of Hospital Cardiologists), Fondazione per il Tuo Cuore, Florence, Italy

Acknowledgements This analysis was carried out under the terms of reference of the WHO Collaborating Centre for Nutrition of the University of Warwick.

Contributors FPC developed the idea, supervised and obtained funding for the analysis, and drafted the manuscript. CJ jointly developed the analytical approach to data handling, carried out the analysis and drafted the analytical part of the manuscript. FPC and CJ contributed equally. SG is the principal investigator (PI) of Progetto Cuore and PS is the PI of MINISAL-GIRCSI. They designed the population studies, obtained funding, supervised the field work and checked the results. CD, LP, RI and DV were directly involved in data collection in different regions, also providing quality control. All authors contributed to the final version of the manuscript. FPC is the guarantor.

Funding This work was supported by the National Centre for Prevention and Disease Control (CCM) of the Italian Ministry of Health (MINISAL-GIRCSI and Meno Sale Più Salute, Osservatorio Epidemiologico Cardiovascolare/Health Examination Survey within the Progetto CUORE coordinated by the Istituto Superiore di Sanità) and The Bupa Foundation (MR-12-002).

Competing interests FPC is an unpaid member of CASH, WASH, the UK National Forum, the UK Public Health NACD; unpaid technical advisor to NICE, the WHO Geneva and Office for Europe, EMRO Region and the Pan American Health Organization; and Trustee of the Student Heart Health Charity. PS is an unpaid member of WASH.

Ethics approval Ethics Committee of the Federico II University of Naples.

Provenance and peer review Not commissioned; externally peer reviewed.

Data sharing statement No additional data are available.

Open Access This is an Open Access article distributed in accordance with the Creative Commons Attribution Non Commercial (CC BY-NC 4.0) license, which permits others to distribute, remix, adapt, build upon this work noncommercially, and license their derivative works on different terms, provided the original work is properly cited and the use is non-commercial. See: http:// creativecommons.org/licenses/by-nc/4.0/

\section{REFERENCES}

1. Fair Society, Healthy Lives. The Marmot Review. Strategic review of health inequalities in England post-2010. The Marmot Review; 2010.

2. Marmot Reviews. http://www.health-inequalities.eu/HEALTHEQUITY/ EN/about_hi/marmot_reviews/ (30 October 2014).

3. Mackenbach JP, Stirbu I, Roskam AJ, et al. Socioeconomic inequalities in health in 22 European countries. $N$ Engl J Med 2008;358:2468-81.

4. Kontis V, Mathers CD, Rehm J, et al. Contribution of six risk factors to achieving the $25 \times 25$ non-communicable disease mortality reduction target: a modelling study. Lancet 2014;384:427-37.

5. Whelton PK, He J, Gail T. Lifestyle modifications for the prevention and treatment of hypertension. Basel, New York: Marcel Dekker, 2003.

6. He FJ, MacGregor GA. A comprehensive review on salt and health and current experience of worldwide salt reduction programmes. J Hum Hypertens 2009;23:363-84.

7. Intersalt Cooperative Research Group. Intersalt: an international study of electrolyte excretion and blood pressure. Results for 24 hour urinary sodium and potassium excretion. BMJ 1988;297: 319-28.

8. Aburto NJ, Ziolkovska A, Hooper L, et al. Effect of lower sodium intake on health: systematic review and meta-analyses. BMJ 2013;346:f1326.

9. Strazzullo P, D'Elia L, Kandala N-B, et al. Salt intake, stroke and cardiovascular disease: meta-analysis of prospective studies. BMJ 2009;339:b4567.

10. D'Elia L, Barba G, Cappuccio FP, et al. Potassium intake, stroke, and cardiovascular disease a meta-analysis of prospective studies. J Am Coll Cardiol 2011;57:1210-19.

11. Appel LJ, Moore TJ, Obarzanek E, et al. A clinical trial of the effects of dietary patterns on blood pressure. DASH collaborative research group. N Engl J Med 1997;336:1117-24.

12. Siani A, Strazzullo $P$, Giacco A, et al. Increasing the dietary potassium intake reduces the need for antihypertensive medication. Ann Intern Med 1991;115:753-9.

13. Stamler J, Elliott $P$, Appel L, et al. Higher blood pressure in middleaged American adults with less education-role of multiple dietary factors: the INTERMAP Study. J Hum Hypertens 2003;17:655-64.

14. Ji C, Kandala NB, Cappuccio FP. Spatial variation of salt intake in Britain and association with socioeconomic status. BMJ Open 2013;3:e002246.

15. Ji C, Cappuccio FP. Socio-economic inequality in salt intake in Britain 10 years after a national salt reduction programme. BMJ Open 2014;4:e005683.

16. Rodriguez-Fernandez R, Siopa M, Simpson SJ, et al. Current salt reduction policies across gradients of inequality-adjusted human development in the WHO European region: minding the gaps. Public Health Nutr 2014;17:1894-904.

17. Strazzullo P, Cairella G, Campanozzi A, et al. Population based strategy for dietary salt intake reduction: Italian initiatives in the European framework. Nutr Metab Cardiovasc Dis 2012;22:161-6.

18. Giampaoli S, Vanuzzo D. La salute cardiovascolare degli Italiani. Terzo Atlante Italiano delle Malattie Cardiovascolari. G Ital Cardiol 2014;15:1s-31s.

19. Protocol for population level sodium determination in 24-hour urine samples. In: Salt-smart Americas: a guide for country-level action. Washington DC: Pan American Health Organization/World Health Organization, 2013:63-89.

20. Donfrancesco C, Ippolito R, Lo NC, et al. Excess dietary sodium and inadequate potassium intake in Italy: results of the MINISAL study. Nutr Metab Cardiovasc Dis 2013;23:850-6.

21. Brezger A, Kneib T, Lang S. Bayes X. Software for Bayesian inference based on Markov Chain Monte Carlo simulation techniques. J Stat Software 2005;14:11.

22. Belitz C, Brezger A, Kneib T, et al. Bayes X-software for Bayesian inference in structured additive regression models. Version 2.1 (on-line). 2012.www.stat.uni-muenchen.de/ bayesx

23. Cappuccio FP, Rink E, Perkins-Porras L, et al. Estimation of fruit and vegetable intake using a two-item dietary questionnaire: a potential tool for primary health care workers. Nutr Metab Cardiovasc Dis 2003;13:12-19.

24. Aburto NJ, Hanson S, Gutierrez $\mathrm{H}$, et al. Effect of increased potassium intake on cardiovascular risk factors and disease: systematic review and meta-analyses. BMJ 2013;346:f1378.

25. World Health Organization. Guideline: sodium intake for adults and children. Geneva: World Health Organization, 2012.

26. Ji C, Sykes L, Paul C, et al. Systematic review of studies comparing 24-hour and spot urine collections for estimating population salt intake. Rev Panam Salud Publica 2012;32:307-15. 
27. Ji C, Miller MA, Venezia A, et al. Comparisons of spot vs 24-h urine samples for estimating population salt intake: validation study in two independent samples of adults in Britain and Italy. Nutr Metab Cardiovasc Dis 2014;24:140-7.

28. Progetto Cuore. http://www.cuore.iss.it (30 October 2014).

29. ScotPHO. Measuring socio-economic inequalities in health: a practical guide. ScotPHO, 2007.

30. Mackenbach JP, Kunst AE. Measuring the magnitude of socio-economic inequalities in health: an overview of available measures illustrated with two examples from Europe. Soc Sci Med 1997;44:757-71.

31. Bonaccio M, Bonanni AE, Di Castelnuovo A, et al. Low income is associated with poor adherence to a Mediterranean diet and a higher prevalence of obesity: cross-sectional results from the Moli-sani study. BMJ Open 2012;2:e001685.

32. World Health Organization. Guideline: potassium intake for adults and children. Geneva: World Health Organization, 2012.

33. McLaren DS. Coronary heart disease in seven countries. The kingdom of the keyses. Nutrition 1997;13:249-53.

34. Bammann K, Gwozdz W, Lanfer A, et al. Socioeconomic factors and childhood overweight in Europe: results from the multi-centre IDEFICS study. Pediatr Obes 2013;8:1-12.

35. Fernandez-Alvira JM, Bammann K, Pala V, et al. Country-specific dietary patterns and associations with socioeconomic status in European children: the IDEFICS study. Eur J Clin Nutr 2014:68:811-21.

36. 'O sale mio (1). https://www.youtube.com/watch?v=Lw8E-0amEuc (30 October 2014).

37. 'O sale mio (2), https://www.youtube.com/watch?v=9KfVHIEup6k (30 October 2014).

38. 'O sale mio (3). https://www.youtube.com/watch?v=h4Vzt-qPb1c (30 October 2014).

39. Accordo con i panificatori. https://www.youtube.com/watch? v=4rJQIHCs4EI (30 October 2014).
40. Cappuccio FP, Capewell S, Lincoln P, et al. Policy options to reduce population salt intake. BMJ 2011;343:402-5.

41. Capewell S, Graham H. Will cardiovascular disease prevention widen health inequalities? PLoS Med 2010;7:e1000320.

42. Hogberg L, Cnattingius S, Lundholm C, et al. Intergenerational social mobility and the risk of hypertension. J Epidemiol Community Health 2012;66:e9.

43. Rao M, Afshin A, Singh G, et al. Do healthier foods and diet patterns cost more than less healthy options? A systematic review and meta-analysis. BMJ Open 2013;3:e004277.

44. Banks J, Marmot M, Oldfield Z, et al. Disease and disadvantage in the United States and in England. JAMA 2006;295:2037-45.

45. McDermott AJ, Stephens MB. Cost of eating: whole foods versus convenience foods in a low-income model. Fam Med 2010;42:280-4.

46. Rehm CD, Monsivais $P$, Drewnowski $A$. The quality and monetary value of diets consumed by adults in the United States. Am J Clin Nutr 2011;94:1333-9.

47. Turrini A, Saba A, Perrone D, et al. Food consumption patterns in Italy: the INN-CA Study 1994-96. Eur J Clin Nutr 2001;55:571-88.

48. Bonaccio M, Di Castelnuovo A, Bonanni A, et al. Decline of the Mediterranean diet at a time of economic crisis. Results from the Moli-sani study. Nutr Metab Cardiovasc Dis 2014;24:853-60.

49. Lorenc $T$, Petticrew $M$, Welch $\mathrm{V}$, et al. What types of interventions generate inequalities? Evidence from systematic reviews. J Epidemiol Community Health 2013;67:190-3.

50. Benach J, Malmusi D, Yasui Y, et al. A new typology of policies to tackle health inequalities and scenarios of impact based on Rose's population approach. $J$ Epidemiol Community Health 2013;67:286-91.

51. Department of Health Responsibility Deal. https://responsibilitydeal dh.gov.uk (30 October 2014).

52. Stamler J, Elliott $P$, Chan Q; for the INTERMAP Research Group. Intermap appendix tables. J Hum Hypertens 2003;17:665-758. 